\title{
Trends in Manufacturing Control
}

\author{
P.J.M. van Bommel \\ Philips CFT Production Systems \\ PO Box 218 \\ 5600 MD Eindhoven \\ The Netherlands
}

\begin{abstract}
Within Philips the Centre for Manufacturing Technology (CFT) is positioned as a R\&D organization, focused on the manufacturing function in the company. The Production Systems department focuses on the specification and design of new production systems and the improvement of existing operations.

The following trends strongly affect manufacturing:

- From manu-facturing to mento-facturing.

- Making use of the hands, but above all the brain power of the workers. This has large implications for the factory organization (example: mini-companies). Therefore it affects also the information flows on the shop floor. When taking into account the trend "from make to buy" it is clear that hierarchical architectures, like the CAM Reference Model (fig. 5), are not suitable anymore. It is replaced by models fitting better to applications available on the market (the Application Reference Model).

- From mass production to mass customization.

- Groups of customers desire personalized products at mass production prices. This implicates multiple manufacturing concepts in the same production organization. The logistics aspects are becoming closely entangled with production aspects.

- Integration of production in the overall business

- Leading to concurrent engineering, extensive work flow control and closer relations between product design and production system design.
\end{abstract}

\section{Keywords}

Shop Floor Control, Architecture, Human aspects, System development approach 


\section{MANUFACTURING EXCELLENCE}

Recently, the manufacturing function within Philips Electronics is receiving a lot of attention. It is recognized that manufacturing is of vital importance for Philips. In order to survive Philips needs to reach world class manufacturing standards [1]. The manufacturing function is reinforced by benchmarking plants with others, both internal Philips and external. This benchmarking is done by means of the so-called Manufacturing Excellence program [2], stating a set of aspects and goals to achieve.

The aspects covered are:

- Organization and culture

- Cycle times

- Quality / customer satisfaction

- Financial measures

- Physical plant

- Product creation process

- Supplier-base management

When scanning through the benchmark list of aspects at a detailed level, emphasizing information and control aspects, we recognize the following trends/issues:

- Empowerment of employees and deployment

- Total employee involvement

- Awareness for customer satisfaction

- Customer involvement

- Integrated information and production systems

- Concurrent product and process engineering

- Order information integrated with manufacturing system

- Supply synchronized with production, without contributing to excess inventory or WIP

- Planning resolution and frequency $\AA 1$ day

- Set-up / change-over times of minutes

- Continuous flow production

- Integrated automation

- CIM with enterprise-wide information interface

- Only value-added automation

- Integrated information system; Production information shared with all employees and linked to company goals

- Maintenance synchronized with production

Based on the observations mentioned above some trends are derived that influence production information systems.

\section{ROUGH CHARACTERIZATION OF PHILIPS MANUFACTURING}

Philips manufacturing has the characteristics of discrete manufacturing: Relatively high volumes of individual products are mass produced in assembly type of plants. Philips plants 
are located world wide. Often the product life cycle is shorter that that of the production means. This requires flexible production systems. As humans are the most flexible elements in manufacturing, human involvement in production is essential.

As the shop floor is continously adapting, it is important to keep changes local in order to keep them manageable. Therefore often a decentralized control architecture is applied. Figure 1 shows some general trends affecting Philips products and production.

\begin{tabular}{|l|c|}
\hline Lead time & $\downarrow$ \\
Total quality & $\uparrow$ \\
Stocks & $\downarrow$ \\
Costs & $\downarrow$ \\
Delivery performance & $\uparrow$ \\
Productivity & $\uparrow$ \\
Time to market & $\downarrow$ \\
Product lifetime & $\downarrow$ \\
Diversity & $\uparrow$ \\
Embedded software & $\uparrow$ \\
Flexibility & $\uparrow$ \\
\hline
\end{tabular}

Figure 1: Issues and trends in discrete manufacturing

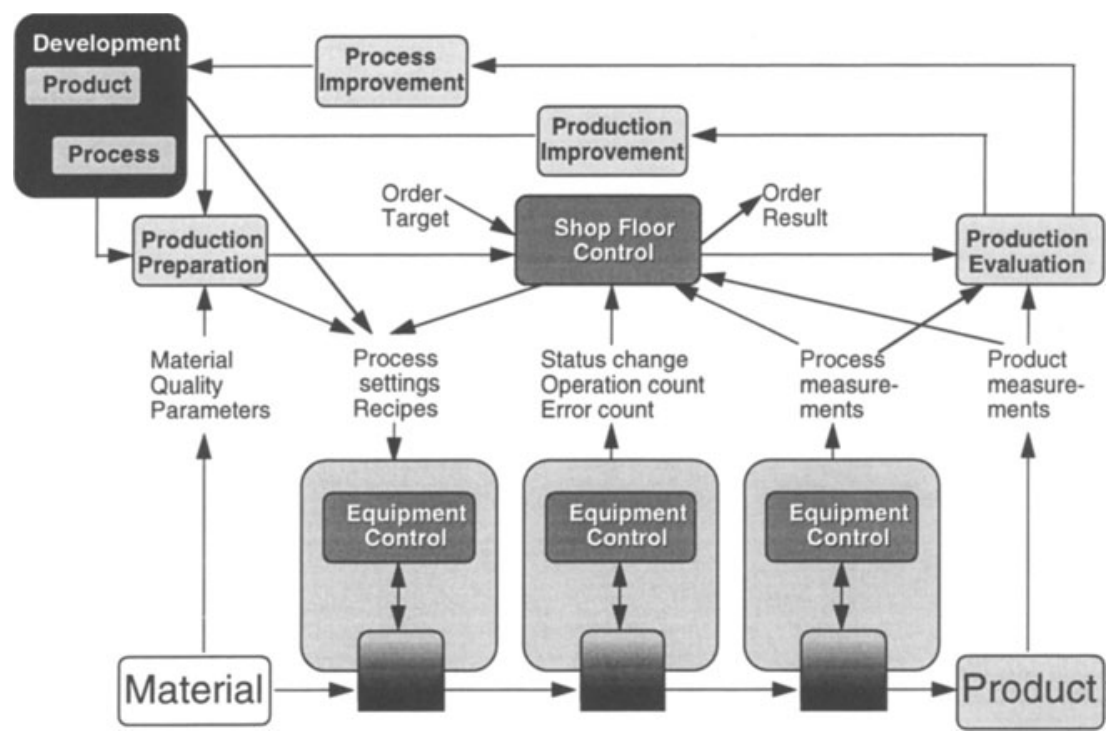

Figure 2: Typical control loops in discrete manufacturing 
Figure 2 shows the typical control loops in discrete manufacturing environments. Essential is:

- The interaction between the improvement cycles, in terms of production and process improvement and development of both product and process.

- The operational order structure of the factory.

Automated support of discrete manufacturing is relatively new. The first area for which software systems for production control were available is continuous production (for example refineries). These type of plants are controlled from a central control room, where all sensors are monitored and actuators, like valves, etc. are controlled. Factory automation concepts started with the central control paradigm [3]. From this centralized form of control the decentralized concepts are derived, especially in the discrete manufacturing environment where flexibility is paramount. See figure 3.
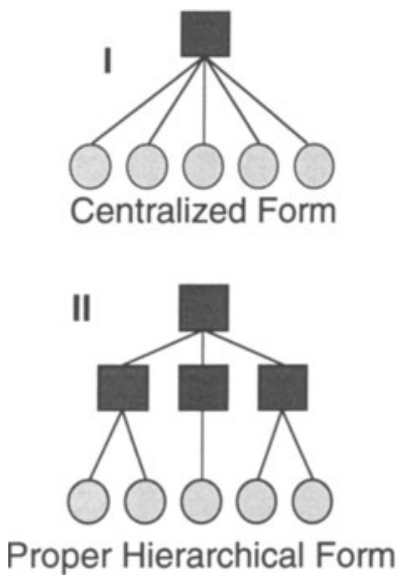
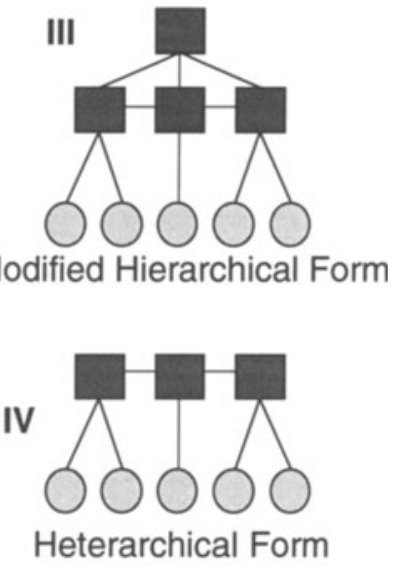

Figure 3: The trend from centralized to (ultimately) heterarchical control structures in manufacturing

\section{FROM “MANU”FACTURING TO “MENTO”FACTURING}

The first trend recognized on the factory floor is the idea to make full use of the brains of the "blue collar" workers. In former manufacturing paradigms workers were performing short cyclic tasks. They were not supposed to think. People were seen as robots, with the disadvantage that they make 'unpredictable' mistakes. At present workers are regarded as the essential capital of a manufacturing enterprise [4, 7]. Not only their physical skills are useful on the factory floor, but also their mental skills.

As is illustrated in figure 4 [5], the quality that is perceived by the customers of a manufacturing enterprise is largely influenced by the people in that enterprise. The people are organized to fulfill the basic processes:

- Product and process development 
- Manufacturing

- Customer support and after sales

Essential in this view is the communication between the people. This is illustrated by the fact that words like People, Teamwork and Organization are directly linked. It is of vital importance that knowledge is shared between all people working in a manufacturing organization.

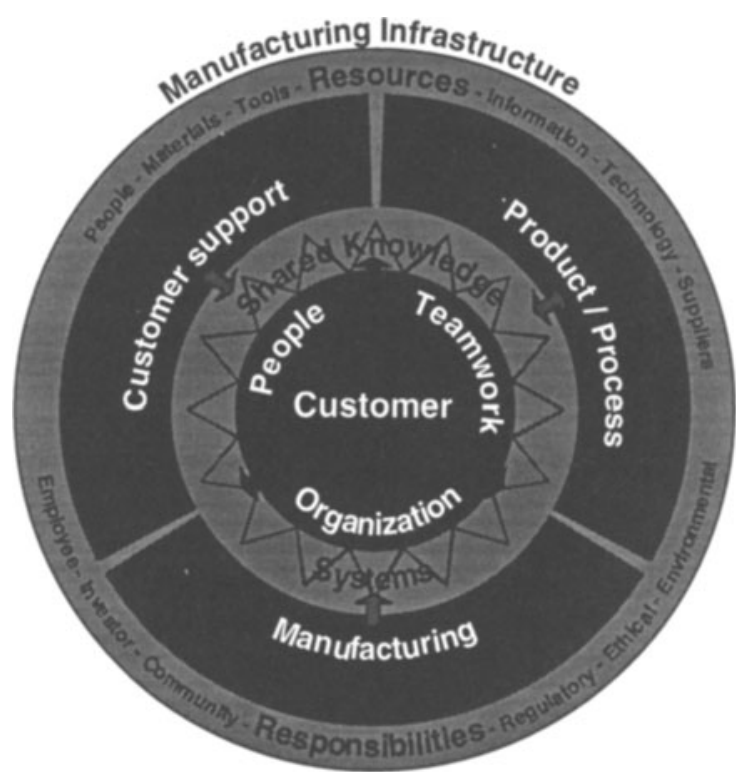

Figure 4: The new manufacturing wheel, emphasizing the central role of people in the manufacturing industry

Focusing on operators on the factory floor, the following trends are recognized:

- The number of operators is decreasing

- The number of machines per operator is increasing

- The functionality and flexibility of machines and therefore their operation complexity is increasing.

- Often the operator is regarded as the 'owner' of his machines, suggesting he has the final word regarding everything that has to do with his machines. The operator therefore has to acquire the skills of a service engineer, quality engineer, etc.. 
As a reaction to these trends especially the user interface of the (increasingly "intelligent") machines is adapted. Knobs and dials oriented and character oriented user interfaces are replaced by graphically oriented user interfaces. At the same time a trend towards multimedia is visible. In this context multi-media is defined as the integrated application of video (graphics, photo's and movies) and audio (Signals and spoken text).

An implication of using the mental skills of the workers is the learning process these workers go through. One of the ways to enable this learning process is to delegate responsibilities and authorities as far down in the organization hierarchy as is possible. This is done by establishing autonomous work groups, also called "mini-companies". Such a mini-company is an operationally oriented unit covering a section of the production chain, aimed at:

- Running the operations as an independent team

- Local improvement and optimization of production

Some essential characteristics are team spirit, a quality drive and use of the practical know how, available on the factory floor.

With respect to the information supply of these mini-companies the following remarks can be made:

- Presentation aspects are important, as performance data are presented to the mini-company members and to others via publication boards (glass wall management)

- The information requirement is continuously changing, due tot the learning curve of the mini-company

- Information must be supplied at the right level of abstraction

- Information must be made available locally

- Information on the information must be available (meta information, stating the meaning of the data presented)

\section{FROM MAKE TO BUY}

Up to now, in discrete manufacturing, production control systems architecture is predominantly hierarchical. In the continuous process industry centralized architectures are used, as is illustrated in figure 2. In cooperation with Digital Equipment Corporation, Philips has developed the CAM Reference Model [6]. This is also an hierarchical architecture as is shown in figure 5.

One of the major disadvantages of the CAM Reference Model is the strictly logical separation of functions between the levels. The CAM Reference Model is used as a blue print of the manufacturing control system architecture during requirements engineering and analysis phase. Never the less the structure of the ultimately implemented control system is often disjunct from the CAM Reference Model. This is due to the fact that system components, available on the market, are not designed according to the CAM Reference Model. The CAM Reference Model is a logical control model, while the ultimate implementation of the control system is according to a IT implementation architecture.

As Philips has no competitive edge in the development of manufacturing control systems it is wise to use solutions available in the market as much as possible. The CAM Reference Model still is an adequate tool to guide the system analysis phase of a shop floor control system development projects, but is far from available components for these systems. 


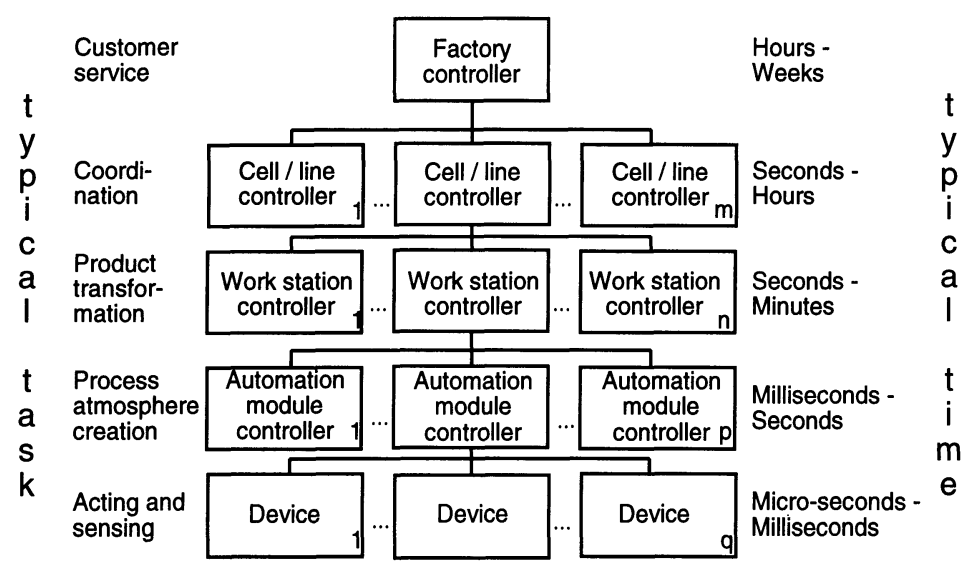

Figure 5: The CAM Reference Model, developed by Philips and DEC

Therefore the CAM Reference Model is replaced by the "Application Reference Model". This model starts with roughly the functionality offered by software packages available in the market. Of course the functionality offered by packages often overlaps that of other packages. But, as a single package solution is not feasible for all types of manufacturing within Philips, the concept of multi-vendor application packages appears sensible. The Application Reference Model is shown in figure 6.

The essential elements of the Application Reference Model are common application packages available in the market. Examples are:

- Enterprise Resource Planning:

- Engineering Data Management:

- Scheduling:

- Maintenance Management:

- Manufacturing Execution 1:

- Engineering Data Analysis:

- Supervisory (Cell) Control (SCADA):
Triton (Baan/4), SAP R/3, MFG/PRO

Sherpa, HP Workmanager

MOOPI, FI-2, Pacemaker, Visual Manufacturing

SAP maintenance module, MAXIMO

Intrack, Workstream, Factoryworks, MESA

IDS

Intouch, FIX-DMACS, Factorylink, Wizcon

None of the vendors of these packages can offer a standard approach to arrive at an integrated system covering the complete scope of manufacturing, although they tend to claim more than they actually offer. A trend is seen towards vendors embarking in partnerships in order to cover the whole set of requirements with their integrated set of solutions An application reference model which describes the complete scope of applications and which relates the application packages to each other therefore is necessary.

When focusing on the system development aspects associated with the use of common application packages available in the market it is recognized that the conventional waterfall type of system development (Figure 7) is not feasible any more. It should be replaced by an incremental approach as shown in the same figure 7. The latter approach uses the Application

1 In literature, maintenance management and scheduling packages are often considered to be part of manufacturing execution. 
reference Model to select application packages covering the key requirements with as little overlap between the functionality of the packages as is possible (i.e. an application framework). When application packages have been selected, the first step is to customize these packages according to the business processes in the manufacturing organization. In terms of these business processes the application functions should be mapped. Selection and customization of a package is the balancing of the user requirements with the restrictions posed by the packages.

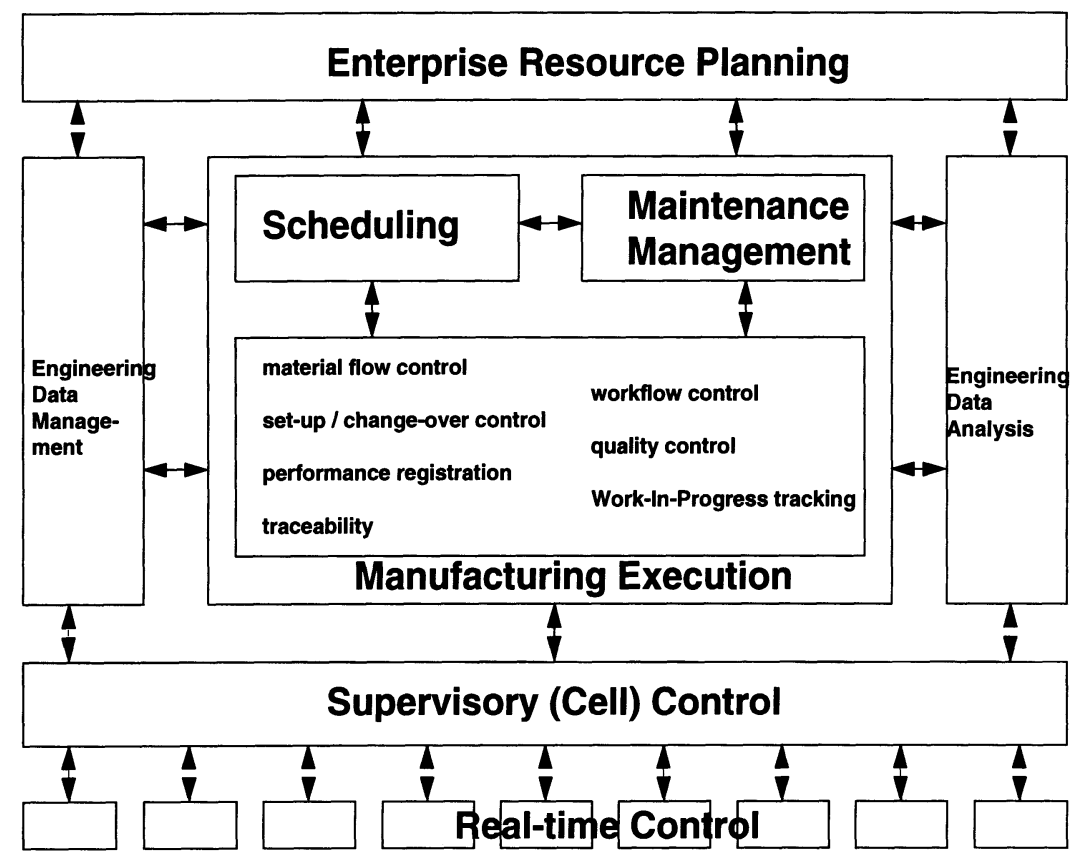

Figure 6: The Application Reference Model, recently developed by Philips

As a consequence of the system development approach and the dynamic nature of the behaviour of the shop floor ( a characteristic of discrete manufacturing), it must be possible to implement or change functionality quite rapidly. This implicates that application packages must be:

- Configurable, being adaptable to the information needs

- Scaleable, being extendable for the size of the organization

- Pluggable, being exchangeable by other more suitable application

- Inter-operable, being able to work together to exchange information using the functionality of several applications.

Therefore, in addition to an application reference model, also a technical architecture is required as part of a CIM framework. A powerful link for shop floor control is an information bus. An information bus provides the interfaces for communication between applications, hiding these interfaces from platform details, like hardware, network and 
databases. Thus we arrive at a preferred technical architecture of shop floor control systems as is shown in figure 8 .

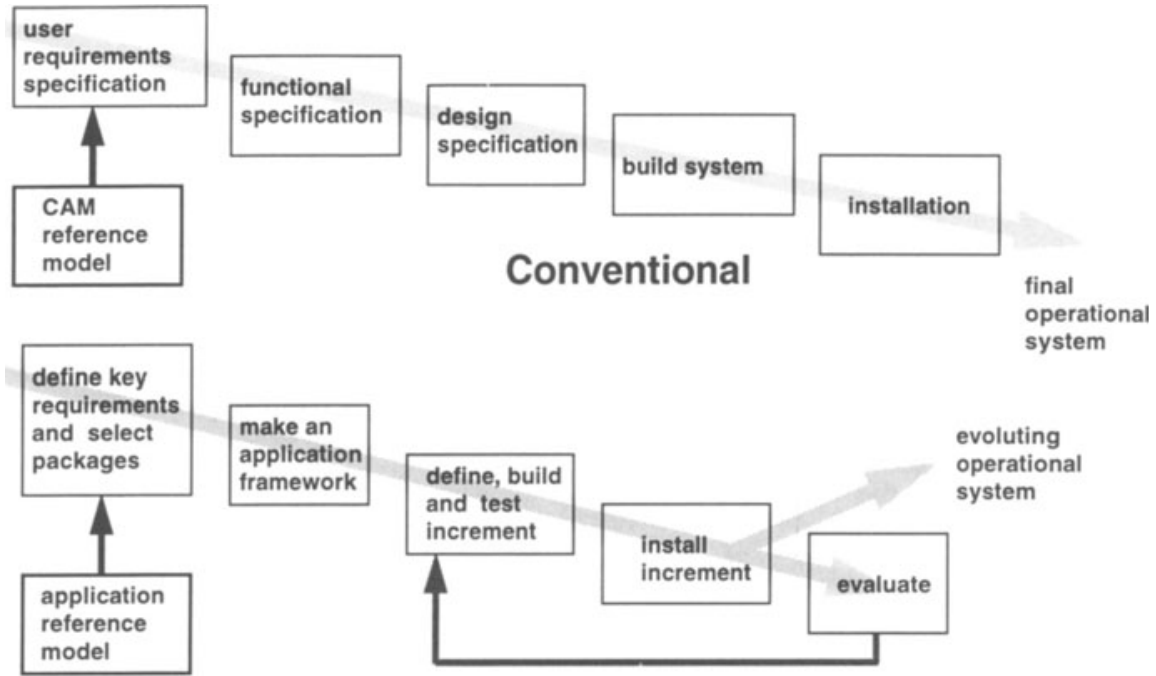

Incremental, using application packages

Figure 7: The conventional and the incremental system development approaches

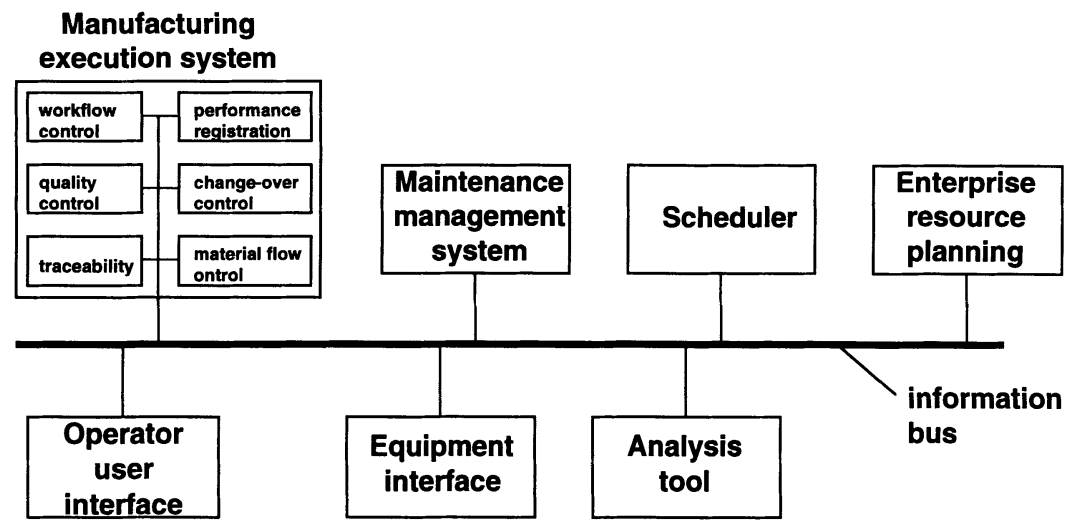

Figure 8: The preferred technical architecture of shop floor control systems

This architecture is based on a mechanism of publishing of, and subscribing to information available in the complete infrastructure. In this way real-time information on order, material, quality, equipment, etc. can be made available and used throughout the manufacturing environment. This event-based approach is indispensable in a shop floor control environment 
and should be regarded as an addition to the demand-based approach of conventional client server architectures.

\section{FROM MASS PRODUCTION TO MASS CUSTOMIZATION}

One of the present challenges, especially in the consumer electronics industry, is the changing paradigm from mass production to mass customization. Personalized products are required, for the price of mass produced ones. This leads to a paradox between the market requirements and the prerequisites for efficient production. This illustrated in figure 9.

\begin{tabular}{|lll|}
\hline & $\begin{array}{l}\text { market } \\
\text { requirement }\end{array}$ & $\begin{array}{l}\text { efficient } \\
\text { production }\end{array}$ \\
\cline { 2 - 3 } order throughput time & $<24 \mathrm{~h}$ & $>1$ week \\
order size & $<100$ & $>2000(1 \mathrm{shift})$ \\
product diversity & $>5000$ & $<100(1 /$ shift / line $)$ \\
product life time & $<6$ months & $>2$ years \\
& $\sqrt{n}$ & $\mathbb{2}$ \\
& $\begin{array}{l}\text { maximum } \\
\text { flexibility }\end{array}$ & $\begin{array}{l}\text { minimum } \\
\text { cost }\end{array}$ \\
\hline
\end{tabular}

Figure 9: The market - manufacturing paradox

The market essentially asks for maximum flexibility of the manufacturing. The manufacturing system itself opposes flexibility as it is required to operate at minimum cost. A way to satisfy these contradicting requirements is the definition of a decoupling point between:

- A mass production factory, with a limited product diversity and a high degree of mechanization / automation

- A highly flexible factory, being able to handle high diversity. Very often this is a flexible manual final assembly operation

Depending on the nature of the product it even is possible to distinguish a third factory type:

- A combination of both types mentioned above, able to cope with moderate product diversity. See figure 10.

In figure 10 the triangles are decoupling points between types of production. The first two, PCB assembly (+ testing) and Sub-assembly (+ testing), are planning driven, while the third one, Configuration, is the demand driven final assembly operation. 


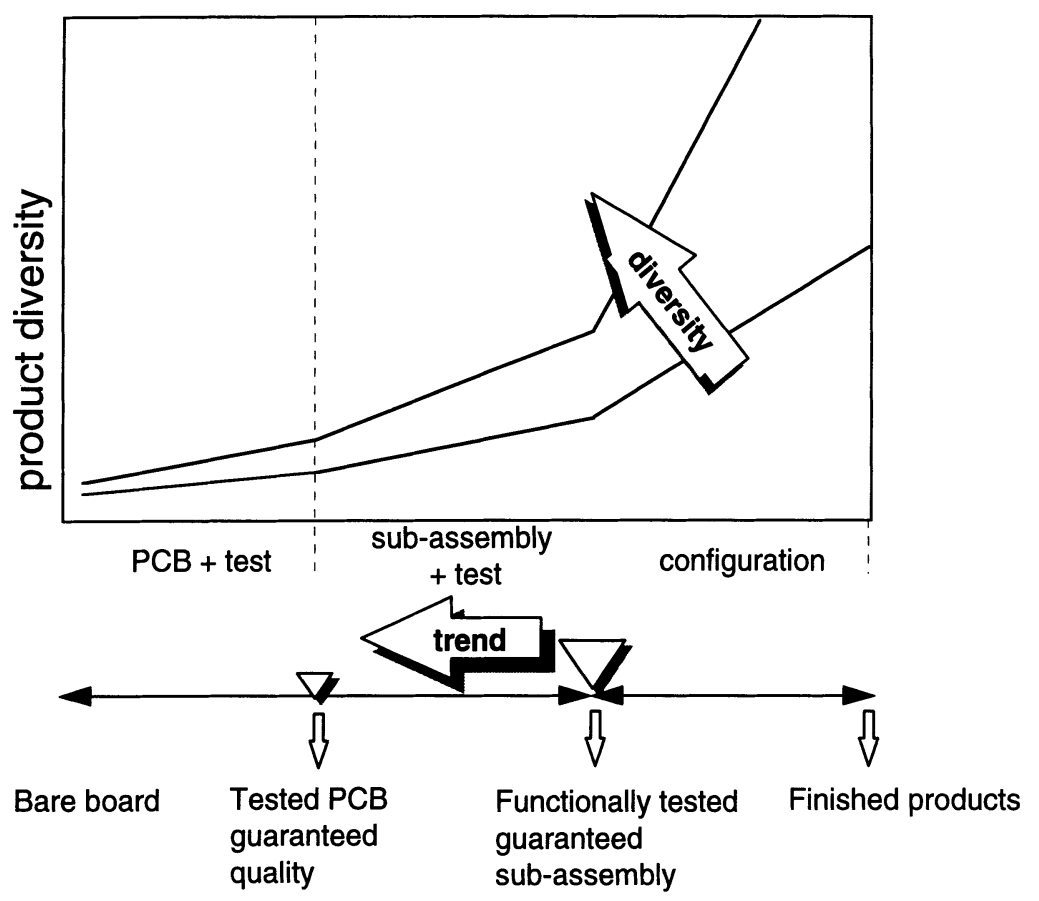

Figure 10: Decoupling point allocation and trend

One of the essentials of this type of manufacturing is that the architecture of the product and production system influence each other directly. This implicates that the manufacturing system must be designed in conjunction with the product (family). The systems used on the shop floor, especially the control systems, must be highly flexible. The incremental system development approach, based on the application reference model fits closely to the demands of such manufacturing systems.

\section{CONCLUSIONS}

Some conclusions to be drawn are:

- The drive for Manufacturing Excellence within Philips is essential to achieve world class manufacturing

- The role of people in the manufacturing process is recognized and emphasized. The control and information systems must fulfill the information requirements of the people on the factory floor as they learn.

- As the role of people on the shop floor is emphasized, the interfacing between humans, machines and control systems is becoming more important. New technology evolves, ultimately leading to multi-media type of human interfaces. 
- Information and control systems play an important role in manufacturing and increasingly will do so.

- The incremental system development approach, based on common application packages available in the market, using the application reference model as guideline, offers excellent opportunities to cope with the requirements of modern manufacturing:

- Emphasis on the role of people on the shop floor

- Trend to mass customization

- Continuous reduction of business cycles

\section{REFERENCES}

[1] T.G. Gunn, " $21^{\text {st }}$ Century Manufacturing, Creating Winning Business Performance"; Oliver Wight Publ., 1992

[2] Philips Corporate Industrial Policy, "Manufacturing Excellence"; Internal publication Philips Electronics, 1994

[3] D.M. Dilts et.al.; Journ. of Manufact. Systems; Vol. 10, No.1, 1991, pp 79-93

[4] Philips Electronics; The Philips values; 1995

[5] Computer and Automated Systems Association / Society of Manufacturing Engineers, "The New Manufacturing Wheel"; USA, 1993

[6] Beukeboom et al., The CAM Reference Model of Production Systems, Philips CFT internal report 01/89, 1989

[7] K. Suzaki, The New Manufacturing Challenge, Free Press, New York, NY, 1987

K. Suzaki, The New Shop Floor Management, Free Press, New York, NY, 1993 